\title{
STUDI PELAKSANAAN KINERJA PERCEPATAN WAKTU PADA PROYEK PEMBANGUNAN GEDUNG BANK DARAH RUMAH SAKIT Dr. SOEDOMO
}

\author{
Widodo Restu Putra*1, Ahmad Ridwan ${ }^{2}$, Yosef Cahyo S P ${ }^{3}$, Agata Iwan Candra ${ }^{4}$. \\ 1,2,3 Fakultas Teknik, Universitas Kadiri. \\ email: *1dodogh.putra01@gmail.com, ${ }^{2}$ ahmad ridwan@unik-kediri.ac.id, \\ 3yosef.cs@unik-kediri.ac.id, ${ }^{4}$ iwan_candra@unik-kediri.ac.id.
}

\begin{abstract}
Dr.Soedomo Trenggalek Hospital has a goal to realize an optimal service for the community through the availability of supporting infrastructures. One of them is the Blood Bank Building Hospital. This study aims to determine how much cost efficiency and time efficiency of the Blood Bank Building construction project at Dr. Soedomo Trenggalek Hospital are accelerated for seven days. The research method used is the " $S$ " Curve method to monitor project implementation in terms of cost and work performance. Furthermore, the Arrow Diagram method is used to speed up the time of project implementation by determining the critical path and paying attention to activities on the critical path to know the activities that need to be accelerated. The Blood Bank Building Construction Project was scheduled to be completed for 120 days with a Budget Plan of Rp. 891,374,000.00. After accelerating seven days to 113 days, a cost increase of Rp. 20,772,189.68. After accelerating 12 days from 120 to 108 days, an increase in costs of Rp. 26,627,020.90.
\end{abstract}

Keywords : Acceleration Of Time, "S" Method Curve, Arrow Diagram (CPM) Method, Budget Plan

\begin{abstract}
Abstrak
Rumah Sakit Dr.Soedomo Trenggalek memiliki tujuan untuk mewujudkan pelayanan yang optimal bagi masyarakat melalui tersedianya sarana infrastruktur pendukung. Salah satunya adalah Gedung Bank Darah Rumah Sakit. Penelitian ini bertujuan untuk mengetahui berapa efisiensi biaya dan efisiensi waktu proyek pembangunan Gedung Bank Darah Rumah Sakit Dr.Soedomo Trenggalek jika dilakukan percepatan selama 7 hari. Metode penelitian yang digunakan adalah metode Kurva "S" untuk memantau pelaksanaan proyek ditinjau dari segi biaya dan prestasi kerja. Selanjutnya, metode Diagram Panah digunakan untuk mempercepat waktu pelaksanaan proyek dengan cara menentukan jalur kritis dan memperhatikan kegiatan - kegiatan pada jalur kritis agar dapat mengetahui kegiatan - kegiatan yang perlu dipercepat. Dalam Proyek Pembangunan Gedung Bank Darah tersebut dijadwalkan selesai selama 120 hari dengan Rencana Anggaran Biaya sebesar Rp. 891.374.000,00. Setelah dilakukan percepatan 7 hari menjadi 113 hari didapat kenaikan biaya sebesar Rp. 20.772.189,68. Setelah dilakukan percepatan 12 hari dari 120 menjadi 108 hari didapat kenaikan biaya sebesar Rp. 26.627.020,90.
\end{abstract}

Kata Kunci : Percepatan Waktu, Metode Kurva “S”, Metode Diagram Panah (CPM), Rencana Anggaran Biaya 


\section{PENDAHULUAN}

Salah satu tuntutan pada era reformasi yang berkembang saat ini adalah memberikan kekuasaan bagi pemerintah daerah untuk pelaksanaan otonomi daerah[1][2][3]. Perubahan paradigma pemerintahan yang semula sentralistik menjadi desentralistik membutuhkan komitmen birokrat dalam mengelola institusi publik [4]. Dalam pelaksanaannya pejabat publik harus mampu memberikan pelayanan kepada masyarakat dengan prinsip Good Governance, yaitu desentralisasi bidang kesehatan dan struktur organisasi yang efektif dan efisien [5].

Rumah Sakit merupakan salah satu bagian yang sangat strategis di bidang Kesehatan [6]. Hal ini tidak lain karena Rumah Sakit yang berkualitas merupakan sarana pelayanan dalam upaya terciptanya Manusia Indonesia yang sehat, segi dari fisik maupun non fisik. Rumah Sakit sebagai salah satu fasilitas kesehatan merupakan bagian dari sumber daya kesehatan yang sangat diperlukan dalam mendukung penyelengaraan upaya kesehatan. Penyelenggaraan pelayanan kesehatan di rumah sakit mempunyai karakteristik dan organisasi yang sangat kompleks[7][8]. Berbagai jenis tenaga kesehatan dengan perangkat keilmuannya masing-masing berinteraksi satu sama lain. Ilmu pengetahuan dan teknologi kedokteran yang berkembang sangat pesat yang harus diikuti oleh tenaga kesehatan dalam rangka pemberian pelayanan yang bermutu, membuat semakin kompleksnya permasalahan dalam rumah sakit [9][10].

Keberhasilan pencapaian indikator pelayanan di rumah sakit tidak hanya ditentukan oleh hasil kerja keras tenaga kesehatan yang ada di rumah sakit [11][12]. Tetapi juga sangat dipengaruhi oleh hasil kerja serta kontribusi positif berbagai instansi terkait lainnya. Oleh sebab itu pembangunan Gedung Bank Darah Rumah Sakit yang masuk dalam pengembangan konstruksi ini sangat dibutuhkan oleh RSUD Dr. SOEDOMO, dimana hal tersebut merupakan salah satu solusi upaya penyempurnaan untuk mewujudkan pelayanan yang optimal bagi masyarakat, Sehingga RSUD Dr. SOEDOMO berharap pembangunan ini mencapai seperti yang diharapkan sesuai waktu yang ditetapkan dan sesuai standart Pembangunan Gedung Bank Darah Rumah Sakit yang sudah di tetapkan [13][14][15].

\section{METODE PENELITIAN}

\subsection{Pengumpulan dan Pengolahan.}

Dalam Pelaksanaan Proyek, dibutuhkan adanya suatu perencanaan yang baik dan sistematis sehingga pelaksanaan dilapangan dapat berjalan lancar sesua dengan tujuan dan rencana. Perencanaan yang baik juga memperkecil timbulnya persoalan dilapangan.

Metode pelaksanaan merupakan suatu metode tata cara dan teknik pelaksanaan pekerjaan. Dengan kata lain metode pelaksanaan pada dasarnya merupakan konsep rekayasa 
yang berpijak pada keterkaitan antara persyaratan dalam dokumen pelelangan, keadaan teknis dan ekonomis yang ada dilapangan. Data - data yang dimaksudkan sebagai berikut :

A. Data Primer.

Data primer adalah data yang diperoleh dari survey atau peninjauan lapangan dengan cara seperti pengukuran lapangan, kondisi lingkungan sekitar proyek, keadaan eksisting proyek dan sebagainya.

B. Data Sekunder.

Data sekunder adalah pengumpulan data yang diperoleh dari instansi atau perusahaan yang terkait yang dalam hal ini diperoleh dari CV. Abadi Surya dengan memperoleh data - data berupa gambar bestek, rencana kerja dan syarat - syarat, rencana anggaran biaya serta jadwal pelaksanaan waktu [16].

\subsection{Pekerjaan Yang Dilaksanakan}

Pada metode pelaksanaan ini dilakukan beberapa pekerjaan yang mendominasi dalam pelaksanaan normal diantaranya adalah Pekerjaan Persiapan, Pekerjaan Tanah, Urugan, Pekerjaan Pasangan Pondasi, Pekerjaan Plesteran, Acian, Benangan, Pekerjaan Beton, DLL. dengan metode sebagai berikut :

A. Metode Perencanaan Pekerjaan

Proyek pembangunan Gedung Bank Darah Rumah Sakit Dr. SOEDOMO Kabupaten Trenggalek ini direncanakan dengan penjadwalan waktu sekitar 4 (empat) bulan. Dalam jangka waktu ini diharap seluruh item pekerjaan yang sudah direncanakan dapat selesai tepat waktu sesuai dengan hari, tanggal, bulan dan tahun yang sudah ditentukan oleh pemilik proyek, dalam hal ini adalah Kontraktor Pelaksana, [17][18][19].

B. Metode Pelaksanaan Pekerjaan

Pada bagian ini merupakan tahapan setelah semua item pekerjaan direncanakan maka kemudian melangkah pada pelaksanaan pembangunan proyek yang pelaksanaannya dimulai pada tanggal 18 Juli 2018 dan harus berakhir atau selesai pada 14 Nopember 2018. Pada kurun waktu yang sudah ditetapkan ini maka - maka pekerjaan - pekerjaan yang dilaksanakan dilapangan harus selesai sesuai dengan urutan pekerjaan yang sudah direncanakan. Pada pelaksanaan pembangunan proyek ini hal - hal yang harus diperhatikan bukan hanya waktu melainkan juga tenaga kerja yang akan dipakai serta biaya pengeluaran selama proses pekerjaan sedanga berlangsung sehingga nantinya akan didapat hasil pekerjaan yang sesuai dengan yang direncanakan serta keuntungan sesuai dengan yang diharapkan.[20] 


\section{HASIL DAN PEMBAHASAN}

\subsection{Prosedur Mempercepat Waktu.}

Sebelum melakukan percepatan waktu, terlebih dahulu menentukan kurun waktu normal. Apabila penjadwalan telah selesai dilakukan hingga didapatkan kurun waktu normal, dapat dilakukan prosedur mempercepat waktu penyelesaian yaitu :

A. Hitungan waktu penyelesaian proyek dan identifikasi float dengan jaringan kerja memakai kurun waktu normal

B. Tentukan biaya normal masing - masing kegiatan

C. Setelah didapat kurun waktu yang telah dipercepat dengan biaya yang paling minimal dapat dibuat penjadwalan kegiatan dengan kurun waktu yang telah dipersingkat.

\subsection{Prosedur Mempercepat Waktu.}

Suatu pekerjaan A dapat dilakukan perhitungan untuk perencanaannya dengan sebagai berikut :

Waktu Normal $\quad: \quad x$, Waktu Percepatan : y, Biaya Normal : $\mathrm{z}$

Biaya Percepatan $: \frac{x}{y} \times z$, Slop Biaya $: \frac{\left(\frac{x}{y} \times z\right)-z}{(x-y)}$

Kenaikan Biaya $\quad:\left(\frac{\left(\frac{x}{y} \times z\right)-z}{(x-y)}\right) \times(x-y)$

Jadi, besarnya kenaikan biaya dapat dihitung dengan cara mengalikan slope biaya dengan selisih waktu normal dikurangi waktu dipercepat. 


\subsection{Analisa Biaya Normal}

Pada Tabel 1. ditampilkan rencanana anggaran biaya proyek secara normal atau sebelum mengalami percepatan prekerjaan.

Tabel 1. Rencana Anggaran Biaya (RAB).

\begin{tabular}{|c|c|c|c|}
\hline No & Uraian Pekerjaan & \multicolumn{2}{|c|}{ Jumlah } \\
\hline I & Pekerjaan Persiapan & Rp. & 2.517.000,00 \\
\hline II & Pekerjaan Tanah dan Urugan & Rp. & $10.057 .764,72$ \\
\hline III & Pekerjaan Pasangan & Rp. & $79.407 .483,82$ \\
\hline IV & Pekerjaan Plesteran, Acian dan Benangan & Rp. & $30.842 .567,02$ \\
\hline V & Pekerjaan Beton & Rp. & 322.867.901,09 \\
\hline VI & Pekerjaan Penutup Atap & Rp. & $20.064 .039,08$ \\
\hline VII & Pekerjaan Lantai & Rp. & 32.371.926.24 \\
\hline VIII & Pekerjaan Rangka Atap, Kusen Pintu + Jendela \& Besi & Rp. & 104.347.708,78 \\
\hline IX & Pekerjaan Cat & Rp. & $12.395 .453,99$ \\
\hline $\mathrm{X}$ & Pekerjaan Pengantung, Pengunci \& Kaca & Rp. & $15.435 .542,60$ \\
\hline XI & Pekerjaan Listrik & Rp. & $95.281 .400,00$ \\
\hline XII & Pekerjaan Sanitasi & Rp. & $24.889 .450,75$ \\
\hline XIII & Pekerjaan Pelapisan Dinding Vynil + Safety Walk Tangga & Rp. & $59.862 .000,00$ \\
\hline & Jumlah & Rp. & $810.340 .238,09$ \\
\hline & PPn $10 \%$ & Rp. & $81.034 .023,81$ \\
\hline & Total & Rp. & $891.374 .261,90$ \\
\hline & Dibulatkan & Rp. & $891.374 .000,00$ \\
\hline
\end{tabular}

Sumber : Analisa Rencana Anggaran Biaya. 


\subsection{Analisa Biaya Akibat Percepatan}

Berikut merupakan pembahasan dari Analisa Biaya Dengan Percepatan Pekerjaan 7 hari dengan Beberapa pekerjaan yang direncananya akan dipercepat yaitu :

A. Pekerjaan Pasangan Batu Bata dengan perhitungan :

Waktu Normal : 14 Hari.

Biaya Normal : : Rp. 39.618.686,00.

Percepatan : 11 Hari.

Biaya Percepatan $: \frac{14}{11} x$ Rp. 39.618.686,00 = Rp. 50.423.782,18.

Slope Biaya $\quad: \frac{R p \cdot 50.423 .782,18-R p \cdot 39.618 .686,00}{14-11}=$ Rp. 3.601.698,73.

Kenaikan Biaya $\quad$ Rp. 3.601.698,73 x (14-11) $\quad=$ Rp. 10.805.096,18.

B. Pekerjaan Kolom Utama 30/30 dengan Perhitungan :

Waktu Normal : 18 Hari.

Biaya Normal $\quad$ : Rp. 37.656.756,90.

Percepatan : 16 Hari.

Biaya Percepatan $\quad: \frac{18}{16} x$ Rp. 37.656.756,90 = Rp. 42.363.851,51.

Slope Biaya $\quad: \frac{R p \cdot 42.363 .851,51-R p \cdot 37.656 .756,90}{18-16}=$ Rp. $2.353 .547,31$.

Kenaikan Biaya $\quad$ : Rp.2.353.547,31 x (18-16) : Rp. 4.707.094,61.

C. Pekerjaan Plat Lantai dengan Perhitungan :

Waktu Normal : 28 Hari.

Biaya Normal $\quad$ : Rp. 68.379.985,47.

Percepatan : 26 Hari.

Biaya Percepatan $: \frac{28}{26} x$ Rp.68.379.985,47 = Rp. 73.639.984,35.

Slope Biaya $\quad: \frac{R p .73 .639 .98435-R p \cdot 68.379 .985,47}{28-26}=$ Rp. $\quad 2.629 .999,44$.

Kenaikan Biaya $\quad$ :Rp. 2.629.999,44 x (28-26) = = Rp. 5.259.998,88.

Total = Rp. $10.805 \cdot 096,18+$ Rp. $4 \cdot 707 \cdot 094,61+$ Rp. $5 \cdot 259 \cdot 998,88 \quad=$ Rp. $20.772 \cdot 189,68$.

Untuk mempercepat pelaksanaan pekerjaan proyek selama 7 Hari, dari 120 Hari menjadi 113 Hari dibutuhkan biaya tambahan sebesar Rp. 20.772.189,68. 


\subsection{Analisa Biaya Akibat Percepatan.}

Berikut merupakan pembahasan dari Analisa Biaya Dengan Percepatan Pekerjaan 12 Hari dengan beberapa pekerjaan yang direncana akan dipercepat yaitu :

A. Pekerjaan Plesteran dengan Perhitungan :

Waktu Normal $\quad: 7$ Hari.

Biaya Normal $\quad$ : Rp. 26.292.211,16.

Percepatan : 5 Hari.

Biaya Percepatan $: \frac{7}{5} x$ Rp. 26.292.211,16 = Rp. 36.809.095,62.

Kenaikan Biaya : Rp.5.258.442,23 x (7-5)

$=$ Rp. 5.258.442,23.

$=$ Rp. 10.516.884,23.

B. Pekerjaan Pengecatan Dinding dengan Perhitungan :

Waktu Normal : 7 Hari.

Biaya Normal : : Rp. 10.096.598,18.

Percepatan : 4 Hari.

$\begin{array}{lll}\text { Biaya Percepatan } & : \frac{7}{4} x \text { Rp. 10.096.598,18 } & =\text { Rp. 17.669.046,82. } \\ \text { Slope Biaya } & : \frac{R p .17 .669 .046,82-R p .10 .096 .598,18}{7-4}=\text { Rp. 2.524.149,55. }\end{array}$

Kenaikan Biaya $\quad$ :Rp. 2.524.149,55 x (7-4) $\quad=$ Rp. 7.572.448,64.

C. Pekerjaan Keramik Lantai dengan Perhitungan :

Waktu Normal : 12 Hari.

Biaya Normal $\quad$ : Rp. 25.613.063,41.

Percepatan : 9 Hari.

Biaya Percepatan $: \frac{12}{9} x$ Rp. 25.613.063,41 = Rp. 34.150.751,21.

Slope Biaya $\quad: \frac{R p \cdot 34.152 .751,21-R p \cdot 25.613 .063,41}{12-9}=$ Rp. $2.845 .895,93$.

Kenaikan Biaya $\quad:$ Rp.2.845.895,93 x (12-9) $\quad=$ Rp. 8.537.687,80.

Total $=$ Rp $\cdot 10.516 .884,23+$ Rp. $7 \cdot 572.448,64+$ Rp. $8 \cdot 537 \cdot 687,80=$ Rp. $26 \cdot 627 \cdot 020,90$.

Untuk mempercepat pelaksanaan pekerjaan proyek selama 12 Hari, dari 120 Hari menjadi 108

Hari dibutuhkan biaya tambahan sebesar Rp. 26.627.020,90. 


\section{KESIMPULAN}

Dari uraian pembahasan pada bab-bab sebelumnya, maka dapat ditarik kesimpulan sebagai berikut :

1. Perencanaan waktu dan biaya Proyek Pembangunan Gedung Bank Darah Dr. SOEDOMO Kabupaten Trenggalek dikendalikan dengan pengendalian Time Schedule yang berupa diagram Bar Chart adalah selama 120 hari kalender dengan total biaya proyek Rp. $891,374,000.00$.

2. Setelah pekerjaan dipercepat menggunakan metode Diagram Arrow selama 7 hari dari 120 hari menjadi 113 hari terdapat kenaikan biaya sebesar Rp. 20.772.189,68.

Sedangkan untuk percepatan 12 hari dari 120 hari menjadi 108 hari terdapat kenaikan biaya sebesar Rp. 26.627.020,90.

\section{SARAN}

Saran - saran yang dapat penulis berikan kepada perusahaan dan atau sub kontraktor adalah Dengan menerapkan Nerwork Planning, perusahaan dapat menyusun penjadwalan tenaga kerja, pengendalian biaya dan pengendalian waktu. Sehingga dalam pelaksanaan pembangunan proyek tersebut berjalan sesuai jadwal perencanaan dan tidak mengalami kerugian. Agar rekanan dapat memperoleh keuntungan, maka harus memiliki pekerjaan yang profesional (ahli) dalam bidangnya dan selalu memakai tenaga lokal (setempat) karena upah lebih murah.

\section{UCAPAN TERIMA KASIH}

Didalam menyusun artikel ilmiah ini saya banyak mendapat bimbingan, petunjuk dan bantuan yang sangat berguna dari berbagai pihak. Oleh karena itu dalam kesempatan ini saya ucapan terima kasih yang sebesar-besarnya kepada pembimbing yang dengan penuh perhatian dan kesabaran memberikan ilmu, bimbingan dan arahan serta rekan Universitas Kadiri yang telah membantu menyelesaikan artikel ilmiah ini. 


\section{DAFTAR PUSTAKA}

[1] N. Ismail, "Pemerintah Desa Dalam Mendukung Tata Pemerintahan Daerah Kabupaten Gorontalo," Gorontalo Law Rev., vol. 1, no. 2, pp. 41-48, 2018.

[2] M. Riduansyah, "Kontribusi Pajak Daerah Dan Retribusi Daerah Terhadap Pendapatan Asli Daerah (Pad) Dan Anggaran Pendapatan Dan Belanja Daerah (Apbd) Guna Mendukung Pelaksanaan Otonomi Daerah (Studi Kasus Pemerintah Daerah Kota Bogor)," Makara Hum. Behav. Stud. Asia, vol. 7, no. 2, p. 49, 2003, doi: 10.7454/mssh.v7i2.51.

[3] H. Prasetiawan, A. Ridwan, and Y. C. S. P, "EVALUASI PENGENDALIAN MUTU PADA PROYEK PEMBANGUNAN OBYEK WISATA SEDUDO DI KABUPATEN NGANJUK," Jurmateks, vol. 2, no. 1, pp. 65-74, 2019.

[4] T. D. Anggraeni, "Menciptakan Sistem Pelayanan Publik yang Baik: Strategi Reformasi Birokrasi dalam Pemberantasan Korupsi," Rechts Vinding, vol. 3, no. 3, pp. 417-433, 2014.

[5] T. Kurniawan, "Pergeseran Paradigma Administrasi Publik: Dari Perilaku Model Klasik dan NPM ke Good Governance,” J. Adm. Negara, vol. 7, no. 23, pp. 1-23, 2007.

[6] M. Aziz, S. Winarto, Y. C. S. P, and A. I. Candra, "STUDI ANALISA PERENCANAAN PERKERASAN LENTUR DAN RENCANA ANGGARAN BIAYA ( PADA PROYEK JALAN RUAS JALAN TAMBELANGAN - DURJAN KABUPATEN SAMPANG )," Jurmateks, vol. 2, no. 2, pp. 235-244, 2019.

[7] L. M. Laurentia, E. P. Setiawati, D. H. Somasetia, and D. Hilmanto, "Gambaran Pelayanan Terintegrasi dan Komprehensif Pada Balita Bawah Garis Merah di Puskesmas Soreang," J. Sist. Kesehat., vol. 2, no. 4, pp. 192-199, 2017, doi: 10.24198/jsk.v2i4.12493.

[8] A. W. Keles, G. D. Kandou, and C. R. Tilaar, "Analisis Pelaksanaan Standar Sasaran Keselamatan Pasien di Unit Gawat Darurat RSUD Dr . Sam Ratulangi Tondano Sesuai dengan Akreditasi Rumah Sakit Versi 2012 Implementation Analysis of Standards Patient Safety Goals in Emergency Department Dr. Sam Ratula,” Jikmu, vol. 5, pp. 250-259, 2015.

[9] A. I. Candra, S. Anam, Z. B. Mahardana, and A. D. Cahyono, "e ISSN 2581-0855 STUDI KASUS STABILITAS STRUKTUR TANAH LEMPUNG,” vol. 2, no. 2, pp. 88-97, 2018.

[10] A. H. Ws, "Perkembangan IPTEK Nuklir Bidang Kesehatan di Indonesia," J. Ilm. Apl. Isot. Dan Radiasi, vol. Vol.4, no. 2, pp. 117-129, 2008, doi: 10.17146/jair.2008.4.2.547.

[11] M. Mandawati, M. J. Fu'adi, and J. Jaelan, "Impact Of Hospital Acreditation: Qualitative 
Study To Nurses In RSUD KRT Setjonegoro Of Wonosobo," Nurscope J. Penelit. dan Pemikir. Ilm. Keperawatan, vol. 4, no. 1, p. 23, 2018, doi: 10.30659/nurscope.4.1.23-29.

[12] E. Mahudi, Y. C. S. P, and A. Ridwan, "STUDI ANALISA DAMPAK LALU LINTAS DIKAWASAN PEMBANGUNAN GEDUNG OLAH RAGA KABUPATEN TRENGGALEK,” Jurmateks, vol. 2, no. 2, pp. 203-213, 2019.

[13] S. R. Yulia, "Jur na $1 \mathrm{R}$ ec hts ind ing Jur $1 \mathrm{R}$ ec hts ind," vol. 1, no. 1, pp. 375-395, 2012.

[14] G. Y. S. T and F. L. S. T, "Analisis Produktivitas Dan Mutu Hasil Tenaga Kerja Konstruksi Pada Pekerjaan Pengecatan Gedung Rumah Sakit Budhi Mulia Pekanbaru,” vol. 1, no. 2, pp. 81-89, 2017.

[15] C. D. Kusuma, Y. T. Mursityo, and W. Purnomo, "Pengembangan Sistem Informasi Rawat Inap dengan Metode Rational Unified Process ( Studi Kasus Rumah Sakit Khusus Hayunanto Medical Center Malang ),” vol. 3, no. 9, pp. 8664-8671, 2019.

[16] I. Ismael and Junaidi, "Identifikasi Faktor-Faktor Yang Mempegaruhi Keterlambatan PelaKsanaan Pekerjaan Pada Proyek Pembangunan Gedung Di Kota Bukittinngi,” J. Momentum, vol. 16, no. 1, pp. 25-36, 2014.

[17] D. Caesaron and A. Thio, "Analisa penjadwalan waktu dengan metode jalur kritis dan pert pada proyek pembangunan ruko (jl. pasar lama no.20, glodok)," J. Ind. Eng. Manag. Syst., vol. 8, no. 2, pp. 59-82, 2015.

[18] O. Aditya and P. Naomi, "Penerapan Manajemen Risiko Perusahaan dan Nilai Perusahaan di Sektor Konstruksi dan Properti,” Esensi J. Bisnis dan Manaj., vol. 7, no. 2, pp. 167-180, 2017, doi: 10.15408/ess.v7i2.4981.

[19] A. Y. Nurkafi, S. Winarto, and A. I. Candra, "ANALISA KINERJA SIMPANG TAK BERSINYAL JALAN SIMPANG BRANGGAHAN NGADILUWIH KABUPATEN KEDIRI," Jurmateks, vol. 2, no. 1, pp. 164-178, 2019.

[20] A. I. Candra, "Pada Pembangunan Gedung Mini Hospital Universitas Kadiri," Ukarst, vol. 1, no. 1, pp. 63-70, 2017. 